\title{
Algunos aspectos de la dialéctica del Parménides desde la óptica hegeliana
}

\author{
Carlos SCHOOF \\ Pontificia Universidad Católica del Perú \\ https://doi.org/I0.I8800/estudiosdefilosofia.20170I.005
}

Resumen: El propósito del presente trabajo es ofrecer un panorama de las afinidades filosóficas entre Platón y Hegel a partir del análisis de la interpretación hegeliana del Parménides. Se mostrará cómo la aproximación hegeliana a Platón y su comprensión del idealismo y la dialéctica están marcadas por el debate con la filosofía kantiana. Esto exige una breve exposición del idealismo trascendental kantiano frente al idealismo absoluto hegeliano, así como de la lógica trascendental kantiana frente a la lógica especulativa hegeliana. Se señalarán luego algunos rasgos hermenéuticos de la interpretación hegeliana de Platón para poder exponer después cómo la primera parte del Parménides admite paralelismos de intención filosófica y hasta narrativos con pasajes de obras de Hegel. Finalmente, se expondrá la evaluación hegeliana del ejercicio dialéctico de la segunda parte del Parménides. Esto exige indicar por qué la dialéctica platónica no logra su cometido filosófico del todo y queda "reducida" a un escepticismo, no desprovisto de valor sino consustancial a toda labor filosófica.

Palabras clave: Hegel, Platón, dialéctica, Ciencia de la lógica, Parménides.

Abstract: "Some Aspects of the Dialectics of Plato's Parmenides from a Hegelian Perspective". The purpose of this paper is to offer a general view of the philosophical affinities between Plato and Hegel through the analysis of the Hegelian interpretation of the Parmenides. We will show how the Hegelian approach to Plato, and his understanding of idealism and dialectics, is determined by Hegel's debate with the philosophy of Kant. A brief exposé of the differences between Kantian transcendental idealism and Hegelian absolute idealism will be needed. Then, we will show some traits of the Hegelian hermeneutics of Plato in order to understand how the first part of the Parmenides admits parallelisms with certain excerpts of Hegel's work, both regarding its philosophical purpose as well as stylistically. Finally, the Author expounds the Hegelian evaluation of the dialectical exercise from the second part of the Parmenides. 
There, Platonic Dialectic fails and does not accomplish its philosophical purpose, and becomes a valuable skepticism consubstantial to philosophical thought.

Keywords: Hegel, Plato, dialectics; Science of Logic, Parmenides.

Como indica Jean-Louis Vieillard-Baron (1991, 429-434), la interpretación hegeliana de Platón es la primera gran interpretación filosófica del siglo XIX del autor de La República y está inscrita dentro de una concepción metafísica del idealismo dialéctico y de una concepción filosófica de la historia de la filosofía. Para Hegel, la actualidad de Platón radica en lo que nuestro pensamiento tiene de platónico y en las posibilidades fecundas latentes en él. De allí la necesidad de "modernizar" los diálogos y el privilegio hermenéutico que merecen aquellos pertenecientes al llamado "período tardío" (especialmente el Teteeto, el Parménides, el Sofista y el Filebo)', hasta entonces muy desatendidos por una tradición exegética que había enfatizado la lectura de diálogos más asequibles y literarios. Hegel encuentra en los diálogos tardíos la consumación más cabal que Platón realizó de su propio pensamiento (aunque la consumación de la dialéctica platónica per se todavía la realizaría -presuntamente- Proclo) y un conjunto de ideas filosóficas que el mismo Hegel perfeccionaría en su Fenomenología del espíritu y su Ciencia de la lógica. Es bastante usual decir que Hegel proyecta su propia filosofía en los filósofos que lee, atribuyéndoles falaz y anacrónicamente conceptos e ideas ajenos a su horizonte. En ese sentido -según Gadamer- Hegel está en oposición a Schleiermacher y la objetivista "reverencia al texto", situándose así dentro de una concepción más bien "subjetivista" de la hermenéutica².

I Al respecto nos dice Gadamer: "[diálogos] que no existían en absoluto para la conciencia filosófica del siglo XVIII y solamente gracias a él [Hegel] fueron reconocidos como el auténtico núcleo de la filosofía platónica por todo el período subsiguiente" (Gadamer 1979, 13).

2 "Para él [Hegel], la comprensión es algo que, también en un sentido muy caro a la hermenéutica, se consigue en la referencia del texto o hecho histórico a comprender a una totalidad de la que es manifestación. Esta totalidad es la Idea, como mediación perfecta entre la subjetividad y la historia. Pero ya no se trata en ella del espíritu que se expresa, sino de la misma subjetividad que entiende. Entendemos un texto cuando lo consideramos como condición de la propia génesis. O dicho con otras palabras: lo importante en él no es lo que quiere decir, sino lo que podemos entender de él, su significado para nosotros, de modo que entendiéndolo nos entendamos a nosotros mismos, haciendo transparente en la tradición histórica la propia génesis del intérprete. La historia queda entonces asimilada en la auto-transparencia conceptual, cuya constitución pertenece a la Filosofía" (Pacheco 1996, 232-233). 
El propósito del presente trabajo es exponer algunos motivos que Hegel pudo haber encontrado interesantes en el Parménides de Platón -sobre todo la naturaleza y función de la dialéctica y su relación con la filosofía, el escepticismo y el idealismo-, mostrando cómo la afinidad de ambos autores puede comprenderse mejor a partir de los conceptos de "negación"y "contradicción" ejemplificados paradigmáticamente según Hegel en dicho diálogo platónico. Se expondrán algunos aspectos de la filosofía platónica y su interpretación hegeliana que resulten propicios para darle un mayor alcance a la investigación y ver quizás qué tan justificada está la acusación hermenéutica antes mencionada.

\section{$\S 1$}

La exposición hegeliana de la filosofía platónica se encuentra de manera dispersa en la Fenomenología del espíritu (1807) y la Ciencia de la lógica (1812-1816), y de manera más cohesionada en el escrito juvenil La relación del escepticismo con la filosofía (1802) y en las Lecciones sobre la historia de la filosofía. Nuestro punto de partida será lo que afirma Hegel en estas últimas sobre la esencia de la filosofía platónica: "[Platón] concibió en toda su verdad el principio de su maestro [Sócrates] según el cual la esencia reside en la conciencia, ya de que acuerdo con él lo absoluto ha de buscarse en el pensamiento y toda realidad es pensamiento: no el pensamiento unilateral o el pensamiento concebido en el sentido del idealismo malo, según el cual el pensamiento reaparece en uno de los lados, se concibe como pensamiento consciente y se enfrenta a la realidad, sino el pensamiento que abarca en una unidad tanto la realidad como el pensar, el concepto y su realidad en el movimiento de la ciencia, y la idea de un todo científico. Así, pues, mientras que Sócrates sólo concebía el pensamiento que es en y para sí como fin para la voluntad consciente de sí misma, Platón abandona este estrecho punto de vista y amplía el derecho puramente abstracto del pensamiento consciente de sí mismo, que Sócrates elevara a principio, llevándolo al terreno de la ciencia (...) lo característico de la filosofía platónica es, precisamente, esa orientación hacia el mundo intelectual y suprasensible, la exaltación de la conciencia al reino espiritual (Hegel 1979, 135-136, cursivas añadidas). 
He subrayado dos cosas: (a) la atribución a Platón de la "identidad del ser y el pensar" y por ende de una filosofía "idealista" y (b) el "movimiento de la ciencia", que no sería otra cosa que el curso dialéctico del pensamiento y también-de acuerdo a lo anterior- de la realidad misma. A mi parecer estos dos puntos articulan la interpretación hegeliana del Parménides y es muy difícil separarlos. Según cierto consenso académico (Guyer y Rolf-Peter 2015), en la filosofía moderna han habido dos concepciones generales y fundamentales del idealismo: por un parte, el idealismo metafísico-ontológico que afirma que algo "mental” (sea la mente, el espíritu, la razón, la voluntad) es el último fundamento de toda realidad, y por otra parte el idealismo epistemológico que aunque concede que hay algo independiente de la mente, defiende que todo lo que podemos conocer acerca de esta "realidad" está permeada por la actividad creativa, formativa o constructiva de la mente. Esta simple bifurcación, claro está, no hace justicia a lo que es el idealismo. Este de por sí es algo demasiado intrincado para ser abordado aquí, por lo que solo manejaré provisionalmente algunas nociones del idealismo en general y del hegeliano en especial, que irán cobrando densidad a lo largo del trabajo pero sin completarse nunca. Así, una caracterización inicial, pertinente y económica, es la de Hartmann: "el fundamento idealista y el principio que configura el sistema hegeliano está en la convicción de que lo 'Absoluto' no es otra cosa que la 'razón' y de que (...) la filosofía no es más que el estallido de ésta, provocado por la razón absoluta y por su elevación hasta ella" $(1960,33)$.

Para echar luces sobre todo lo anterior y su relación con Platón hay que comprender qué es el "idealismo malo" en oposición al "idealismo genuino" del que habla Hegel en las Lecciones. Considérese la Enciclopedia de las ciencias filosóficas, donde Hegel explica que un idealismo malo es un idealismo subjetivo, es decir, "que no se abandona al contenido, que sólo atiende a las formas abstractas de la subjetividad y objetividad y se detiene, precisamente de manera unilateral, en la primera de ellas, en la forma de la subjetividad como última determinación simplemente afirmativa" (Hegel 1999, 146). El contexto en el que se gesta este juicio es inevitablemente el del resultado "solipsista" de la Crítica de la razón pura: las categorías del entendimiento tienen su origen en la unidad de la autoconciencia y por consiguiente todo lo que podemos conocer a través de ellas no contiene nada objetivo. Es decir, el sujeto y el objeto quedan inexorablemente divorciados y son pensados unilateralmente como determinaciones opuestas. El entendimiento no puede salir de su 
esfera para llegar a lo real porque conduce a contradicciones. En el reino de la contradicción se vuelve razón especulativa que debe ser "puesta en su sitio" policialmente por el mismo entendimiento y su modesto aparato categorial. Es interesante considerar la apreciación hegeliana de la facultad kantiana del "entendimiento" (Verstand), ya que la verdadera dialéctica como ejercicio de la "razón" (Vernunft) superará las contradicciones del primero al ver la mediación entre las determinaciones contrarias y podrá pensar sinópticamente lo real, arribando así al idealismo verdadero. La oposición y valoración de ambas facultades correspondería a la de la diánoia y la noēsis en Platón (Hegel 1979, 174-177), y es en esos términos precisos que se evalúan para Hegel los méritos ambiguos del Parménides. En oposición al idealismo subjetivo, el idealismo genuino es entonces el fruto maduro que la conciencia conquista a través del itinerario dialéctico de sus figuras, cuando cae en la cuenta de que "pasando a otro, [es que] algo sólo viene a coincidir consigo mismo y [que] esta referencia a sí mismo en el pasar y en lo otro es la verdadera infinitud (...). Así el ser ha sido reproducido, pero como negación de la negación, y es el ser-para-sí” (Hegel 1999, 197). Es decir, "En el ser-para-sí ha ingresado la determinación de la idealidad. El existir, captado primeramente sólo según su ser o según su afirmación, tiene realidad (...) y por tanto, también la finitud está primeramente bajo la determinación de la realidad. Pero la verdad de lo finito es más bien su idealidad. Igualmente, también lo infinito del entendimiento, si se coloca junto a lo finito, y siendo así solamente uno de los dos finitos, es un no-verdadero, [algo] ideal. Esta idealidad de lo finito es el principio capital de la filosofía y toda verdadera filosofía es por ello idealismo. En definitiva, todo consiste en no tomar como infinito a lo que por su misma determinación se convierte a la vez en un particular y finito" (Hegel 1999, 199).

Kant mostró perfectamente que la razón especulativa genera conceptos por sí misma, que este proceso sigue una necesidad peculiar, anhelando arribar a lo incondicionado o absoluto, y que la razón en su proceso dialéctico conduce necesariamente a contradicciones; pero lo que Hegel lamenta es que Kant no vio que todo esto se da en la realidad y no solo en la conciencia. Queriendo refutar a Hume, Kant propuso que los sujetos trascendentales compartimos una estructura cognitiva que regula nuestra experiencia fenoménica y hace posible el conocimiento. Sin embargo, no podemos salir de nuestra estructura racional jamás e ir al mundo tal como es (de allí el residuo de la cosa-en-sí). Para 
Hegel la filosofía kantiana lleva al escepticismo (y veremos que algo semejante opina de Platón), pero el idealismo y la dialéctica hegeliana mostrarán cómo sí podemos conocer la realidad porque el pensamiento y la realidad son lo mismo: "Anaxágoras viene alabado por haber sido el primero en formular el pensamiento de que el Nous, el Pensamiento, es el principio del mundo, y de que hay que determinar la esencia del mundo como pensamiento. Con esto se ha echado el fundamento de un modo intelectual de ver el mundo, modo cuya pura figura tiene que ser la lógica. Ésta no tiene que ver con un pensar sobre algo que de por sí, fuera del pensar, yaciera como fundamento, ni con formas que debieran entregar meras notas de la verdad, sino que las formas necesarias y las determinaciones propias del pensar son la verdad suprema misma" (Hegel 2011, 199).

Desde entonces, idealismo, dialéctica y lógica son indisociables. Sólo habrá idealismo donde haya una lógica dialéctica bien llevada a cabo. Que Hegel haya encontrado en Platón una ocurrencia genial pero ambigua del idealismo no debe ser pasado por alto, pero para llegar al idealismo platónico hay que sobrepasar dificultades hermenéuticas y filosóficas.

\section{$\S 2$}

El trabajo de Vieillard-Baron ha demostrado a partir de un examen minucioso de las fuentes y versiones de las Lecciones que la aproximación hegeliana a Platón se realiza a partir del tema de la forma de la filosofía platónica. Hegel considera que el atractivo estilístico y mítico del diálogo es fuente de equívocos porque "el mito es siempre una exposición mezclada (...) con imágenes dirigidas a los sentidos y aderezadas para la representación, y no para el pensamiento; lo cual no indica sino la impotencia del pensamiento mismo, que aún no sabe andar sin andaderas y que no es aún, por tanto, un pensamiento libre" (Hegel 1979, I5I); y advierte que "para captar la filosofía de Platón a base de sus diálogos, es necesario que sepamos distinguir lo que es simple representación (...) y lo que es la idea filosófica misma" $(1979,52)$. Es preciso ejercer cierta violencia hermenéutica ya que de lo contrario "o bien se encuentra demasiado en la filosofía platónica, como es el caso de los neoplatónicos, que alegorizan sus 
mitos convirtiéndolos en filosofemas ${ }^{3}$; o bien se encuentra demasiado poco, como los modernos, que la reducen a dicho contenido mítico desprovisto de valor conceptual” (Barrios 1995, 132). No es de extrañar por ello que el Parménides merezca un privilegio hermenéutico, ya que allí no asistimos a la puesta en escena de ningún mito, sino a la exposición de la dialéctica entre figuras de la talla de Parménides, Zenón y Sócrates, contado incluso para una audiencia de mala philosophoi (Platón 2005, 127b). Pero, ¿qué es lo que Hegel considera debe reinterpretarse para llegar a Platón? Como se constata en las Lecciones y señalan muchos intérpretes: por un lado, la noción de anámnesis y la inmortalidad del alma; por otro, el estatuto ontológico ("trascendente") y epistemológico ("formal" e "innata") de las Ideas.

Cuando Platón afirma que "aprender es recordar" no se preocupa por expresar una concepción empírica de la adquisición del conocimiento sino algo relativo a su esencia. El conocimiento es "la unidad mediadora consigo misma de la conciencia y la esencia” (Hegel 1979, 153) y "la verdadera naturaleza de la conciencia consiste en ser espíritu, en el cual, como tal, existe ya aquello que es su objeto o que la conciencia está llamada a ser para sí” (1979, 163, cursivas añadidas). La reminiscencia no debe ser entendida pues como la reproducción de una representación a través de la memoria sino como Erinnerung, como un hacerse-algo-interior: "el alma ya es en sí misma lo que está llamada a ser para sí, de manera que su aprender esta verdad, su erkennen, constituye un proceso inmanente de auto-despliegue" (Barrios 1995, 133). Hegel lee así, por ejemplo, la alegoría de la caverna, donde los prisioneros se elevan de la conciencia y la captación sensible de lo en-sí a la autoconciencia o el para-sí (Barrios 1995, 133). La ciencia brota de la conciencia porque el conocimiento es autoconocimiento, una reminiscencia permanente dentro del ser-consigo-mismo [Beisichsein]. El alma conoce las cosas y las Ideas, pero en sentido estricto nunca sale de ella misma. Es importante resaltar que para Platón el "alma [es] algo que se mueve a sí mismo y que es, en este sentido, un momento del espíritu” (Hegel 1979, 166). No es sustancia sino espíritu, auto-movimiento [Selbstbewegung], autokínesis, y dicho movimiento no es otra cosa que el mismo pensamiento. Por ello para Platón "la inmortalidad del alma depende directamente del hecho de que el alma es de suyo lo pensante" (Barrios 1995, 134) y no de que ha 
pre-existido en algún cielo inteligible antes de su encarnación en un cuerpo, como la forma mítica parece sugerir.

Sobre el estatuto epistemológico y ontológico de las Ideas, Hegel dice que "hay que abandonar (...) la extraña manera de captar las ideas platónicas (...) como si fueran cosas existentes, pero en otro mundo o región, fuera de la cual se encontraría el mundo de la realidad efectiva con una sustancialidad real diversa de aquellas ideas (...). La idea platónica no es otra cosa que lo universal o, de un modo más determinado, el concepto del objeto" (Hegel 20II, 256). Dado que la lectura hegeliana es la primera lectura moderna nodualista de Platón (Barrios 1995, 133) y que Hegel descubre filosóficamente los diálogos tardíos, es imposible no conjeturar que la primera parte del Parménides donde se advierten varias interpretaciones erróneas de las Ideas debió parecer interesante a Hegel. Para él, parafraseándolo, la idea platónica es lo que suele llamarse "lo general", pero no concebido como lo general formal, que es solamente una cualidad de las cosas, sino como lo que es en y para sí, como la esencia, como aquello únicamente verdadero. Las ideas no son meros conceptos formales porque poseen un contenido determinado, $y$ son causa de la determinación de las cosas. Hegel teme que se homologue a la idea platónica con una suerte de concepto general que sea solo la abstracción de las cosas particulares. Eso estaba insinuado en la cita sobre el "idealismo malo" que revisamos anteriormente. Para Hegel la idea es "un género concebido más bien por el pensamiento y para él” (Hegel 1979, I59-160) y "lo que Platón llama absoluto es (...) algo único e idéntico consigo mismo, algo concreto de suyo, en cuanto que es un movimiento que retorna a sí mismo y que permanece enteramente para sí" $(1979,160)$. Además, Platón "puso al descubierto el mundo intelectual, pero sin ver en él un mundo situado más allá de la realidad, en el cielo, en un lugar distinto, sino el mundo real" (1979, 160), ya que de lo contrario no tendrían ninguna función epistémica y serían superfluas. Veamos los paralelismos incluso narrativos con el Parménides.

Cunado Hegel insiste en que las ideas no son meros "objetos del pensamiento" (nóémata) parece hacer eco de Parménides y la conclusión absurda que se sigue de que cada una de las Ideas sea sólo "un pensamiento sobre ellas, que no puede acontecer en ninguna otra parte sino en las almas” (Platón 2005, 132b-c). En el contexto de Hegel, resultaba común identificar a las ideas platónicas con ideas innatas o conceptos o esquemas estrictamente intra-mentales. Hegel 
no puede admitir esta lectura porque en la medida en que Platón defiende la tesis de que "ser y pensar son lo mismo" no puede ser un mero conceptualista o negar darle un contenido a las Ideas. Ellas son para Platón determinadas en sí mismas, y son principio de determinación de las cosas. Por si fuera poco, el mismo Platón quiere seguir determinando a las ideas de manera más cabal, por lo que no pueden ser meros esquemas formales.

Hegel también reniega de la interpretación de las ideas como cosas "trascendentes" y hace eco así de Parménides 132d-133ª donde el filósofo homónimo trae a colación con Sócrates la noción de la idea como arquetipo. Hegel explica $(1979,162)$ que si vemos a las Ideas como un simple pensamiento nuestro o como cosas situadas fuera de él en otra realidad hemos fracasado en comprender la noción de paradigma. Primero, porque estamos tomando a las ideas como "cosas" (algo que todo el Parménides se preocupa por rechazar y mostrar como absurdo) y porque el paradigma es para Hegel algo "en y para sí". Si separamos las ideas de la realidad estaríamos cayendo en un dualismo de corte kantiano: sujeto y objeto, pensamiento y realidad, permanecen contemplados unilateralmente como opuestos sin lograr elevarnos hacia su unidad. Debemos resolver dicha diferencia en la autoconciencia y su proceder dialéctico. Y además, Hegel se hace eco de otro punto del Parménides: sin Ideas no hay dialéctica, y sin dialéctica no hay conocimiento. Por ello, como dice Platón en el Parménides, las Ideas son los supuestos necesarios del pensamiento: "Sin embargo, Sócrates -continuó Parménides-, si por las anteriores dificultades y otras similares, alguien no admitiese la existencia de las Ideas de las cosas o no distinguiese una Idea determinada en cada caso, no tendrá hacia dónde dirigir su pensamiento, ya que no admite que la Idea de cada cosa permanezca siempre la misma, con lo que se destruirá enteramente el poder de la dialéctica" (Platón 2005, 135c). Hegel opina algo semejante en la Enciclopedia cuando afirma que "lo dialéctico constituye el alma móvil del proceder científico hacia adelante y es el único principio que confiere conexión inmanente y necesidad al contenido de la ciencia, del mismo modo que en él reside en general la verdadera y no extrínseca elevación sobre lo finito" (Hegel 1999, 184).

Con estas clarificaciones hermenéuticas ya hemos entrado al Parménides y solo queda ver la evaluación ambigua que hace Hegel de la dialéctica platónica 
en ese diálogo. Para Hegel, una interpretación neoplatónica vuelve a Platón un dogmático (Planty-Bonjour 1982, 5). Sin embargo, la dialéctica platónica no tiene nada que ver con emanaciones del ser, sino con la negatividad. No es en lo absoluto una filosofía dogmática sino una filosofía escéptica, y tal es la enseñanza peculiar del Parménides.

\section{§ 3}

En el $\$ 79$ de la Enciclopedia, Hegel dice que "lo lógico, según la forma, tiene tres lados: $\alpha$ ) el abstracto o propio del entendimiento; $\beta$ ) el dialéctico o racionalnegativo; $\gamma$ ) el especulativo o racional-positivo" (Hegel 1999, 182). Estos no son partes de la disciplina de la lógica formal sino "momentos de todo lo lógico-real, es decir, de todo concepto o de todo lo verdadero" (1999, 183). El momento abstracto es el momento de la fijación, en el que los conceptos parecen tener una definición o una determinación estable, allí "el pensamiento (...) se queda parado en la determinidad fija y en la distintividad de ella frente a otra" (I999, 183). El momento dialéctico es "el propio superar de tales determinaciones finitas y pasar a sus opuestas" (1999, 183); es un "rebasar inmanente en el cual se expone la unilateralidad y limitación de las determinaciones del entendimiento" (1999, 183) haciendo que ellas mismas se desestabilicen y pasen a sus contrarios. El momento especulativo "aprehende la unidad de las determinaciones en su oposición" (1999, 184) arribando a un resultado positivo que niega y preserva lo anterior, y tiene un contenido porque no se queda en la "mera negación" o "mera nada", sino que es una negación determinada, por ello no es un resultado formal sino concreto. El proceso anterior en su completitud constituye el método filosófico-dialéctico hegelianoy el despliegue de lo real en su racionalidad. Ahora bien, el problema del Parménides consiste, según Hegel, en que allí Platón solo ha permanecido en el momento dialéctico (ilustrándolo de manera genial pero limitada) sin arribar a lo especulativo. Desarrollemos este diagnóstico y veamos qué apoyo textual puede haber. Recordemos que para Hegel "hay filosofía dialéctica cuando se descarta la positividad de la intuición intelectual para poner en primer plano la absoluta negación de la razón; cuando la inmovilidad de una sustancia estática es reemplazada por el devenir universal de determinaciones fluidas; cuando finalmente la identidad 
vacía es reemplazada por la contradicción viviente" (Planty-Bonjour 1982, 4-5) $)^{5}$. ¿Ocurre algo de esto en el Parménides?

En las Lecciones, Hegel (1979, 177-189) advierte que la dialéctica platónica como procedimiento tiene tres aspectos: i) tiene la finalidad de embrollar y disolver las representaciones finitas para provocar en la conciencia la necesidad de la ciencia y la tendencia hacia lo que en verdad es ${ }^{6}$, ii) llevar a la conciencia solamente a lo universal (la Idea) y iii) seguir determinando la Idea en sí misma ${ }^{7}$. Los momentos (i) y (ii) no serían exclusivos de Platón porque los comparte con los sofistas ${ }^{8}$, mientras que sólo el momento (iii) permitiría unificar las contradicciones y llegar a la dialéctica especulativa que la filosofía requiere, transformando el "entendimiento" en "razón" y la diánoia en nóesis. Sin embargo, Platón tiene demasiados problemas para llegar a ese tercer momento. Para Hegel, el carácter aporético de los diálogos platónicos muestra dicha deficiencia. El pensamiento se queda en la mera negación o la mera nada, llega a abolir las cosas finitas y las apariencias y por ello no puede establecer la unidad de lo finito y lo infinito: la dialéctica platónica, expuesta en el Parménides, tiene, por una parte, la sola intención de disolver y refutar por sí misma afirmaciones restringidas; mientras que, por otra parte, tiene en general la nada como resultado (Hegel 1979, I8I). El Parménides se encuentra entre los diálogos aporéticos por su conclusión: "tanto que haya un Uno como que no lo haya, él y los Otros, con respecto a sí mismos y en sus relaciones, son absolutamente todo y no lo son, parecen serlo y no lo parecen" (Platón 2005, 166c) Sin embargo, este carácter aporético puede salvarse si se considera los diversos sentidos de Unidad que Platón trabaja y es atento a señalar

$5 \quad$ La traducción del francés es nuestra.

6 Considérese el siguiente pasaje del diálogo en cuestión: "no permitirás que la investigación se extravíe en las cosas visibles, sino que te dirigirás ante todo hacia aquellas que sólo pueden captarse por la razón y que podemos llamar Ideas" (Platón 2005, 135e).

7 "(...) cada idea contiene mucho de ser y mucho de no-ser. Una idea es lo que es, y no es una multitud de otras cosas; junto con su determinación positiva, con su unidad y su identidad, contiene siempre una multiplicidad de diferencias negativas; esto es lo que hace necesaria la aparición de una Idea superior que incluya en una síntesis más amplia, en una determinación más comprensiva, las Ideas inferiores que han servido de punto de partida" (Fouillé 1943, p. 2I).

8 Lo cual resulta curioso por lo que dice en otro lado: “Lo que Sócrates y Platón llaman sofistería no es otra cosa que la argumentación raciocinante a partir de razones; Platón contrapone a ello la consideración de la idea, e.d. de la Cosa en y para sí misma, o sea en su concepto" (Hegel 20II, 52I). 
y distinguir. El Uno de la primera deducción no es el mismo del que se sigue hablando en otros momentos del diálogo, y así podríamos hacer un recorrido de distinciones entre por ejemplo el Uno-Uno, el Uno-ente, el Uno-todo, y así sucesivamente de acuerdo a la argumentación platónica en cada momento del ejercicio dialéctico.

Platón dirige su dialéctica contra el mundo finito; tiene por objetivo mostrar la finitud de las representaciones y de las determinaciones particulares del entendimiento y del sentido común, que ellos toman por verdaderas, para así introducir el escepticismo que es esencial para toda filosofía. En La relación del escepticismo con la filosofía Hegel rechaza el juicio de Schulze según el cual el escepticismo antiguo era un mero "dudar" y completamente opuesto al ímpetu filosófico. Para Hegel el escepticismo es un enfático negar, es el momento dialéctico del pensamiento, y como momento del despliegue lógico-real, es completamente consustancial a la filosofía. Además, “iAcaso podríamos encontrar documento y sistema más perfecto y acabado del escepticismo antiguo que en la filosofía platónica del Parménides? Él deja en ruina todo ese saber del entendimiento a través de conceptos" (Hegel en Bonjour 1982, 5). Hegel está considerando desde luego la segunda parte del Parménides, es decir, el ejercicio dialéctico, y lo hace a partir de lo que dice Parménides en I37b sobre el "trabajoso juego" de la dialéctica. Hegel lo toma al pie de la letra: es un juego completamente serio ya que lo que está sobre la mesa no es nada menos que el conocimiento filosófico mismo, la aprehensión y despliegue del Absoluto y el acceso al punto de vista idealista. Sin embargo, no deja de ser por ello un juego y en la medida en que sus reglas están mal diseñadas fracasamos al jugarlo. ¿Qué reglas son estas? La estructura judicativa de sujeto y predicado. Hegel en su Lógica cuestiona "la validez de la estructura proposicional del entendimiento para expresar verdades especulativas, puesto que en ella se pone al sujeto como a un fundamento fijo, haciendo de sus determinaciones algo exterior, sin que pueda llegar a expresar entonces el auto-movimiento del concepto, por el cual no sólo se alcanza la universalidad del pensamiento, sino que en ella se reconoce a sí misma la propia subjetividad” (Barrios 1995, 139).

Para Hegel el movimiento del pensamiento no puede ser arbitrario, debe venir del trabajo negativo que ejerce la razón. Pero cuando Parménides enuncia las hipótesis y deducciones, juega con proposiciones comunes del tipo "no es múltiple, ni un todo de parte; no tiene límites, ni extensión, ni figura" (Platón 
2005, 137c-138a), “no está en ningún lugar" (Platón 2005, I38b), "no está en reposo ni en movimiento" (Platón 2005, 138b-139b), etcétera. Platón sigue usando "puntos de vista particulares" que no pueden elevarse sobre su finitud hacia la infinitud, sino sólo quedar negadas. Por ello, según Hegel aparecen ideas de manera arbitraria, sin necesidad, y además cuando la Idea aparece desde fuera no se preservan los contenidos de los que se ha estado discutiendo. Platón destruye escépticamente todas las proposiciones sin retener su contenido, y por ello no puede llegar a un resultado positivo. No reconoce en esa universalidad la subjetividad consciente de sí, no ve detrás de todo ese discurso sobre el Uno el protagonismo del Absoluto y de la razón de manera adecuada. Esto es curioso ya que, trayendo a colación la importancia que tiene para Hegel la unidad y a la vez la distinción de la forma del diálogo platónico, él mismo niega que los diálogos sean genuinamente diálogos, sino una exposición "monológica” de un pensamiento (Planty-Bonjour 1982, 9). $Y$ es justo en la segunda parte del Parménides donde las intervenciones casi siempre paupérrimas del joven Aristóteles parecen dar apoyo textual a esa observación hegeliana. En lo más cerca que Platón ha estado de exponer su pensamiento completo y condensado, allí es donde menos recurre a la forma dialógica. $Y$ aun así no ha sido suficiente.

¿Dónde sí triunfa la dialéctica platónica? Recordemos que presuntamente "la dialéctica platónica no pretende disolver el rígido concepto eleático del ser, sino también lo que él llama allí la dialéctica ordinaria y raciocinante (räsonierende)" (Barrios 1995, 136). Lo segundo no lo logra del todo, pero lo que sí hace es "refutar a la vez el sistema jonio de la multiplicidad pura y el sistema eleático de la pura unidad. Para esto, no hace sino concebir más completamente la unidad misma, imperfectamente comprendida por Xenófanes y Parménides, y el último resultado de la dialéctica es percibir en este principio mismo de la unidad el principio de la distinción" (Fouillé 1943, 79). El apoyo textual a estas afirmaciones lo encontramos en la primera hipótesis del Parménides; allí podemos encontrar un elenchos del ser de Parménides, que conlleva a todo lo contrario a lo que el mismo Parménides consideraba. Así, por mencionar algunos ejemplos, en I37c-I38b se deduce que si el Uno es, no es un todo, contrariamente a lo que Parménides decía; en I38b se deduce que no puede estar en el mismo sitio, no puede yacer, también oponiéndose a Parménides; además, en esa misma hipótesis resulta interesante ver cómo mientras Parménides llega de la afirmación de que el ser no se genera ni se mueve a que 
está en reposo, Platón parte de lo mismo pero llega un resultado inverso. Estas y otras ocurrencias que no mencionaré ni explayaré nos dejan conjeturar que en esta sección Platón no sólo critica a Parménides, sino a sus sucesores y sus interpretaciones. Claro está, lo anterior no quiere decir ni debe ser confundido con que la teoría que el Parménides del diálogo quiere probar es la del Parménides histórico y su poema, esto porque el Parménides histórico no conoce las Ideas, porque el poema habla de que el ser es uno, no de que el Uno es, y porque el ser del poema es determinado, y no apeiron como el de la primera hipótesis.

En conclusión, la interpretación hegeliana de Platón pone al descubierto los aspectos más profundos del pensamiento de Platón tal como se expresa en el Parménides, y lo hace en conexión con problemáticas que resultaban apremiantes para ambos filósofos y por motivos quizás no tan distintos. Sin embargo, Hegel parece omitir los sentidos de unidad que el Parménides presenta, y que matizaría mucho el juicio general que tiene de dicho diálogo, sin perder por ello intuiciones interesantes que hay en el ejercicio dialéctico que Platón ejemplifica allí, sentando un camino para la dialéctica que tendrá muchas repercusiones en el futuro filosófico.

\section{Bibliografía}

Barrios, M., 1995. Hegel: una interpretación del Platonismo. Anales del Seminario de Metafísica 29, 125-148.

Fouillé, A., 1943. La filosofía de Platón. Madrid: La España Moderna.

Gadamer, H., 1979. La dialéctica de Hegel. Cinco ensayos hermenéuticos. Madrid: Cátedra.

Hartmann. N., 1960. La filosofía del idealismo alemán. Buenos Aires: Editorial Sudamericana.

Hegel, G.W.F., 1979. Lecciones sobre la historia de la filosofía. México D.F.: FCE.

- 1999. Enciclopedia de las ciencias filosóficas. Madrid: Alianza Editorial.

— 201I. Ciencia de la lógica I. La lógica objetiva. Madrid: Abada.

Pacheco, J., 1996. Corrientes actuales de la filosofía, Madrid: Tecnos.

Guyer, P.y R.-P. Horstmann, 2015. Idealism. http://plato.stanford.edu/entries/idealism/. Consultado 27 de noviembre de 2015. 
Planty-Bonjour, G., 1982. Hegel et la dialectique selon les grecs. Revue internationale de phislophie 36, 3-20.

Platón, 2005. Parménides. Madrid: Alianza Editorial.

Vieillard-Baron, J.-L., I99I. L'actualité de la dialectique de Platon à la lumière de Hegel. Revue philosophique de la France et de l'Étranger I8I, 429-434. 